\title{
Pagetoid polyostotic fibrous dysplasia
}

\author{
Rashmi Maruti Hosalkar, ${ }^{1}$ Jigna Pathak, ${ }^{1}$ Niharika Swain, ${ }^{1}$ Neeta Mohanty ${ }^{2}$
}

'Department of Oral Pathology and Microbiology, MGM Dental College and Hospital, Navi Mumbai, Maharashtra, India

${ }^{2}$ Department of Oral Pathology and Microbiology, Institute of Dental Sciences Siksha 0 Anusandhan University, Bhubaneswar, Odisha, India

\section{Correspondence to} Dr Neeta Mohanty, dr.neetamohanty@gmail.com

Accepted 20 April 2015

\section{SUMMARY}

Fibrous dysplasia (FD) is a benign skeletal lesion occurring due to mutation of Gs $\alpha$ gene and involves one or multiple bones. We present a case of a 30 -yearold female patient, with a 1-year history of swelling under her right eye that had gradually increased in size. Extraoral examination revealed a diffuse swelling extending anteroposteriorly from preauricular region to nasolabial fold, frontonasal region and superoinferiorly from zygoma to body of mandible, causing ipsilateral proptosis and contralateral deviation of nose. Intraoral examination showed obliteration of right upper and lower buccal vestibule. CT disclosed expansile lytic lesions involving multiple skull bones, jaws, sternum, rib and thoracic vertebrae. Histopathology displayed broad and interconnected trabeculae connected to the host bone exhibiting reversal lines resembling the mosaic pattern of Paget's disease. These features suggested pagetoid polyostotic FD. The patient underwent cosmetic recontouring and is under regular follow-up postoperatively.

\section{BACKGROUND}

Depending on the number of bone involved, fibrous dysplasia (FD) is generally classified as monostotic FD (MFD; single bone affected) and polyostotic FD (PFD; multiple bones affected). Although craniofacial bone involvement can occur in both types of FD, polyostotic variant is more prevalent. ${ }^{1}$ The most affected bones in decreasing order for MFD are cranial bones, facial bones, rib, femur, tibia, humerus and those in PFD are femur, tibia, cranial bones, facial bones, pelvis, rib, upper extremities and clavicle. Only $1.4-5.5 \%$ of all FD lesions reported spinal involvement of which, lumbar spine is the most commonly affected followed by thoracic, sacral and cervical. ${ }^{2}{ }^{3}$ Based on the diverse histopathological features in correlation with the clinical occurrence and event of prenatal genetic mutation, FD can be classified into three types: Chinese letter pattern, pagetoid pattern and hypercellular pattern. ${ }^{4}$

To the best of our knowledge, on rigorous PubMed/MeduInE search, the present case is the first of its kind to report occurrence of sternum, rib and cervical vertebra involvement in histopathological pagetoid variant of polyostotic FD.

\section{CASE PRESENTATION}

A 30-year-old woman presented with a 1-year history of swelling under her right eye that had gradually increased in size. On extraoral examination, a large, ill-defined swelling measuring approximately $8 \times 6 \mathrm{~cm}$ was noted on the right side of face extending anteroposteriorly from preauricular region to

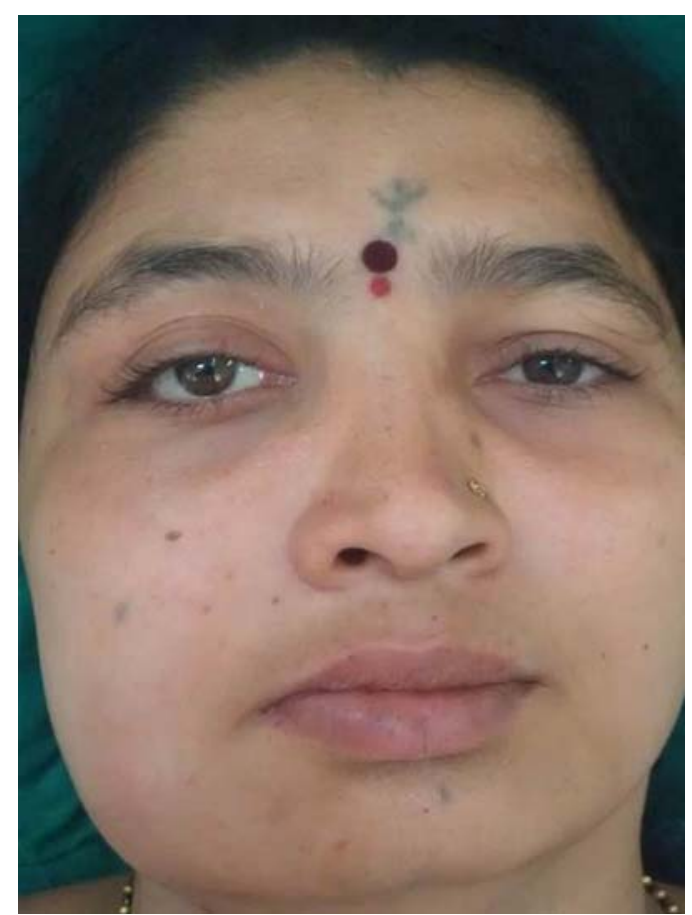

Figure 1 Extraoral view showing unilateral swelling involved the right side of face.

nasolabial fold and frontonasal region and superoinferiorly from zygoma to body of mandible (figure 1 ), causing ipsilateral proptosis (figure 2) and contralateral deviation of nose. Functional deformity was absent. On intraoral examination, the swelling caused obliteration of the right maxillary and mandibular buccal vestibule in relation to 14-17 and 44-47 regions.

\section{INVESTIGATIONS}

Radiologically, the posteroanterior view and lateral view of skull revealed expansile lytic lesions involving right frontal, parietal, temporal, zygomatic, maxillary and mandibular bones. The lesions show ground glass attenuation in diploic spaces of calvarium; medulla could not be differentiated from the cortex (figures 3 and 4). CT of the head and neck revealed diffuse ill-defined expansile ground glass



Figure 2 Extraoral view showing proptosis of right eye. 


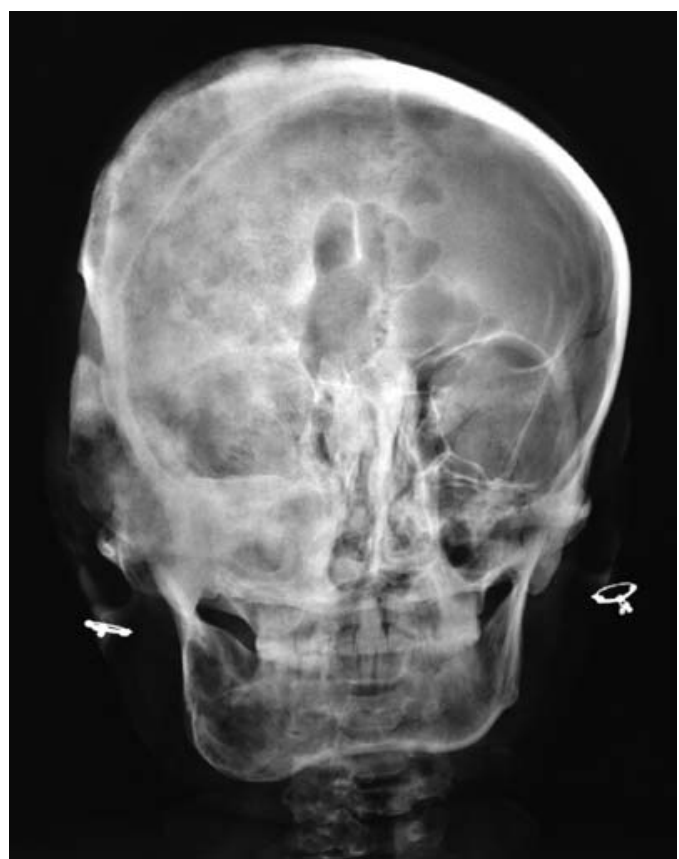

Figure 3 Posteroanterior view of skull revealed expansile lytic lesions involving right frontal, parietal, temporal, zygomatic, maxillary and mandibular bones. lesions in right frontotemporoparieto-occipital calvarium, right sphenoid, base of skull, petrous part of right temporal, right medial wall of ethmoid bone, right lateral wall of orbit, right zygomatic process, right maxilla, right mandible and vomer bone (figures 5 and 6). Proptosis could also be observed and measured with the help of CT (figure 7). ${ }^{5}$ CT of the chest showed lytic expansive lesions in the sternum, rib and thoracic vertebrae (figure 8).

Biochemical tests such as serum alkaline phosphatase, serum calcium and serum hormonal levels were in normal limits.

On microscopic examination, the tissue revealed, irregular, bony trabeculae in a collagenous stroma with varying degree of cellularity and vascularity (figure 9). The broad and interconnected trabeculae showed reversal lines resembling the mosaic pattern of Paget's disease (figures 10 and 11). No evidence of osteoblastic rimming and lamellar bone were evident. Fusion of lesional and host bone was seen. A bone biopsy from C4 vertebrae correlated with the above histopathological findings.

On correlating the clinical, radiological and histopathological findings the diagnosis of pagetoid PFD was performed.

\section{DIFFERENTIAL DIAGNOSIS}

Differential diagnosis such as Paget's disease and ossifying fibroma was considered before favouring the diagnosis of FD.

Paget's disease usually occurs in older age group and shows marked elevation in serum alkaline phosphatase levels as

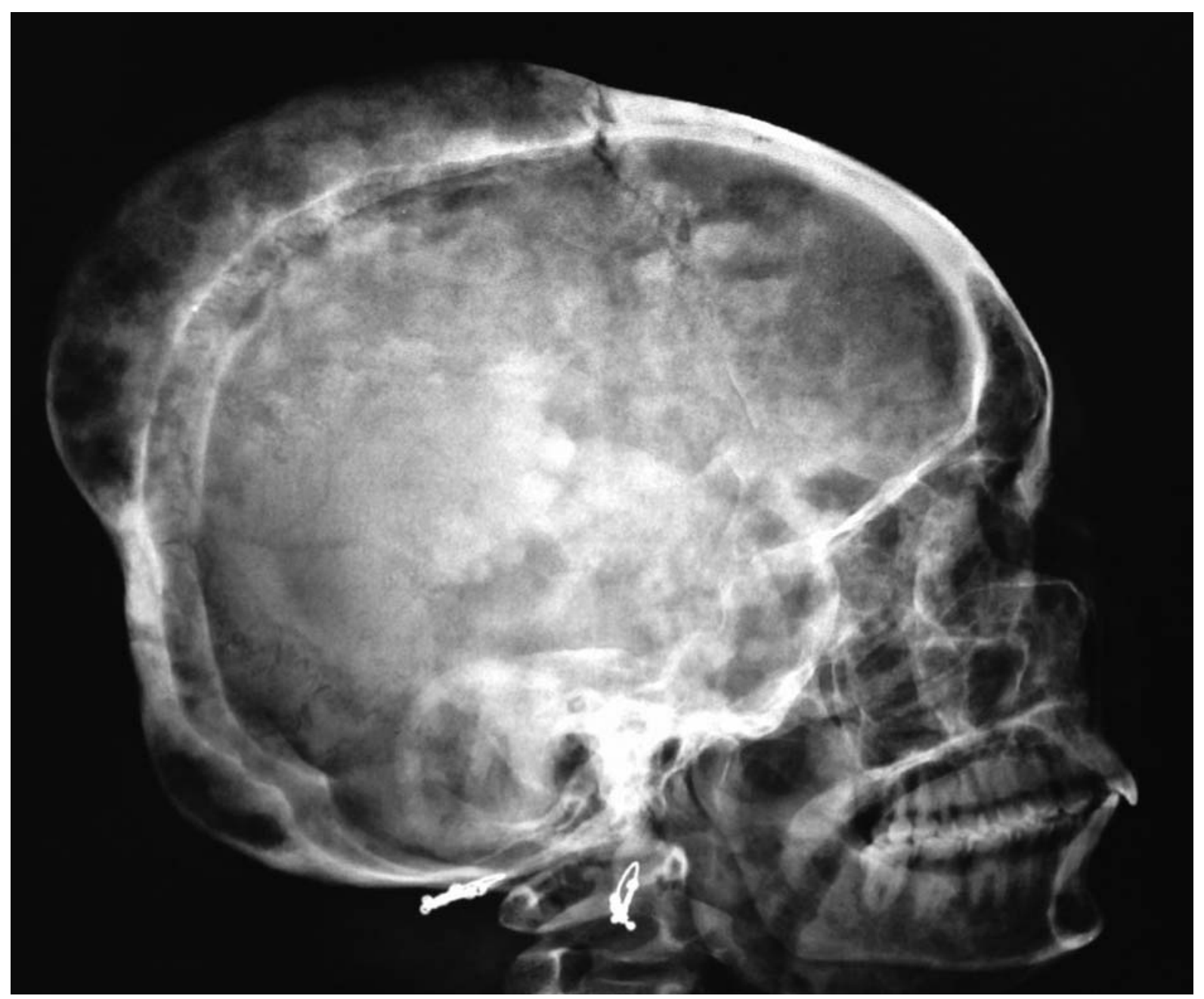

Figure 4 Lateral view of skull revealed expansile lytic lesions involving right frontal, parietal, temporal, zygomatic, maxillary and mandibular bones. 


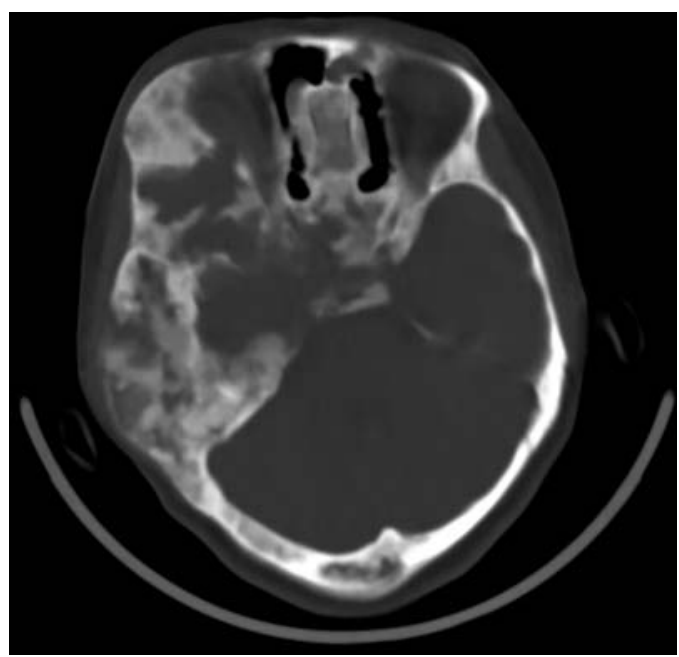

Figure 5 CT of the head showing diffuse ill-defined expansile ground glass lesions involving craniofacial bones.

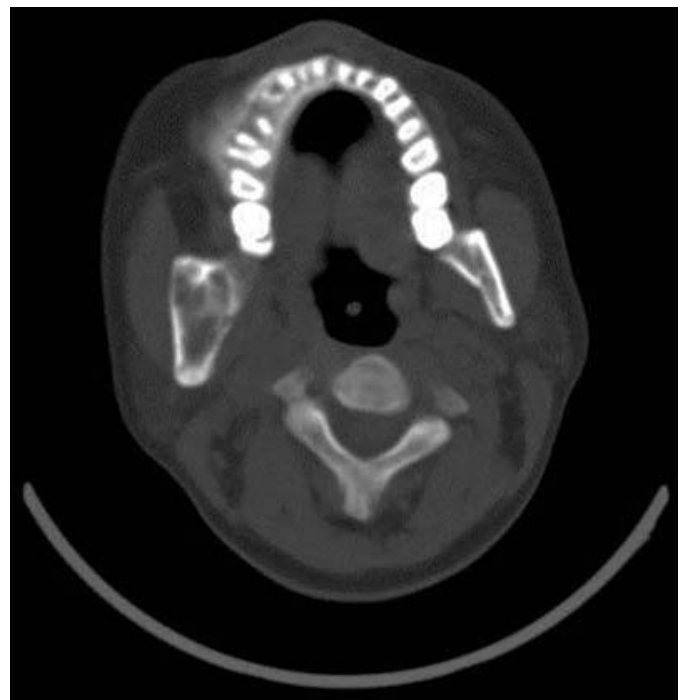

Figure 6 CT scan of the head showing diffuse ill-defined expansile ground glass lesions involving maxilla.



Figure 7 CT scan showing proptosis in right eye.

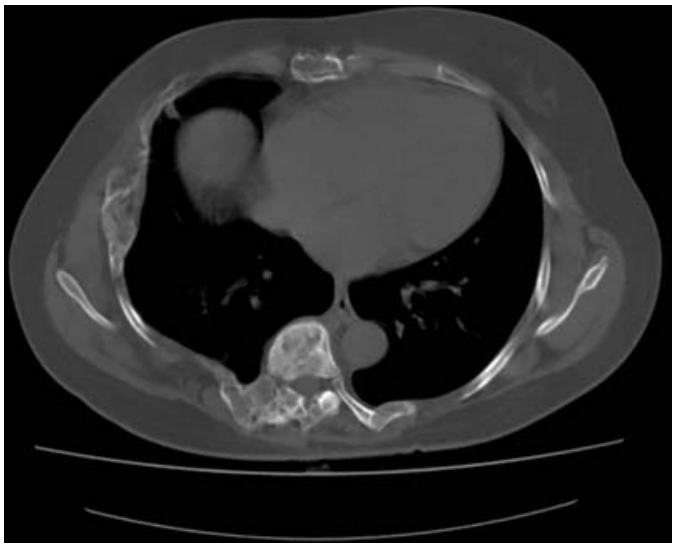

Figure 8 CT of the chest showing diffuse ill-defined expansile ground glass lesions involving thoracic vertebrae, fourth rib.



Figure $9 \mathrm{H} \& \mathrm{E}$-stained decalcified tissue showing irregular, bony trabeculae in a collagenous stroma with varying degree of cellularity and vascularity (×100 magnification).

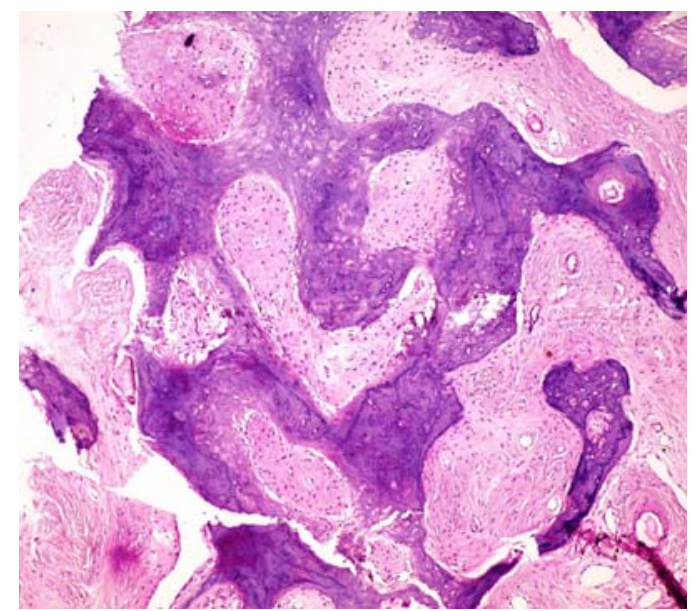

Figure 10 H\&E-stained decalcified tissue showing broad and interconnected trabeculae showing reversal lines resembling the mosaic pattern of Paget's disease ( $\times 100$ magnification). 


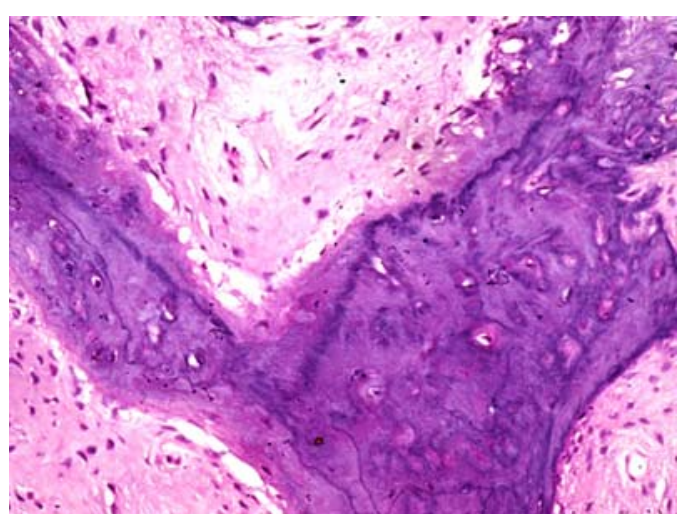

Figure 11 H\&E-stained decalcified tissue showing broad and interconnected trabeculae showing reversal lines resembling the mosaic pattern of Paget's disease ( $\times 400$ magnification).

compared with that of FD. ${ }^{6}$ Histopathologically, pagetoid variant of PFD and Paget's disease share common feature such as jigsaw/mosiac pattern. Presence of features such as broad interconnected trabeculae, fusion of lesional bone to the host bone and peritrabecular clefting differentiates pagetoid variant of PFD from Paget's disease.

Ossifying fibroma, a relatively common fibro-osseous lesion has similar clinical features as FD, that is, age, sex predilection and gnathic bone involvement. Well-delineated radiological presentation and distinct histopathological features such as fibrous tissue that exhibits varying degree of cellularity, mineralised material along with basophilic cementum such as hard tissue and poorly cellular spherules can easily differentiate ossifying fibroma from pagetoid variant of PFD. ${ }^{7}$

\section{TREATMENT}

The present case was managed by surgical recontouring of the facial bones.

\section{OUTCOME AND FOLLOW-UP}

The patient is on routine follow-up since a year and has had no further symptoms. (figure 12).

\section{DISCUSSION}

In 1891, Von Recklinghausen reported a case and termed it as osteitis fibrosa generalisata that was later replaced by the term FD which was introduced by Lichtenstein in 1938 who described it as 'perverted activity of bone forming mesenchyme'. ${ }^{8}$ Of all fibro-osseous lesions FD accounts for only 1$2 \%$. In benign bone tumours, $5-7 \%$ is FD. ${ }^{9}$

$\mathrm{FD}$ is a sporadic fibro-osseous lesion, generally caused due to postzygotic missense mutations of the gene those code for $\alpha$ subunit of the stimulatory G protein, Gs, in the GNAS complex locus in chromosome 20q13.2-13.3. The pathogenesis of FD in relation to occurrence of genetic mutation is depicted in figure $13 .{ }^{10}{ }^{11} \mathrm{FD}$ can be classified as MFD and PFD. MFD is associated with single bone while PFD involves multiple bones. PFD is further classified as craniofacial FD where only the craniofacial complex is affected and PFD associated with syndromes such as Lichtenstein-Jaffe-type syndrome and Albright's syndrome. Lichtenstein-Jaffe type involves multiple bones, café au lait pigmentations on the skin with rare association of endocrinopathies and Albright's syndrome is associated severe unilateral PFD, café au lait pigmentations on the skin and various endocrinopathies. ${ }^{12}$ Ten per cent cases of MFD and 50\% to all

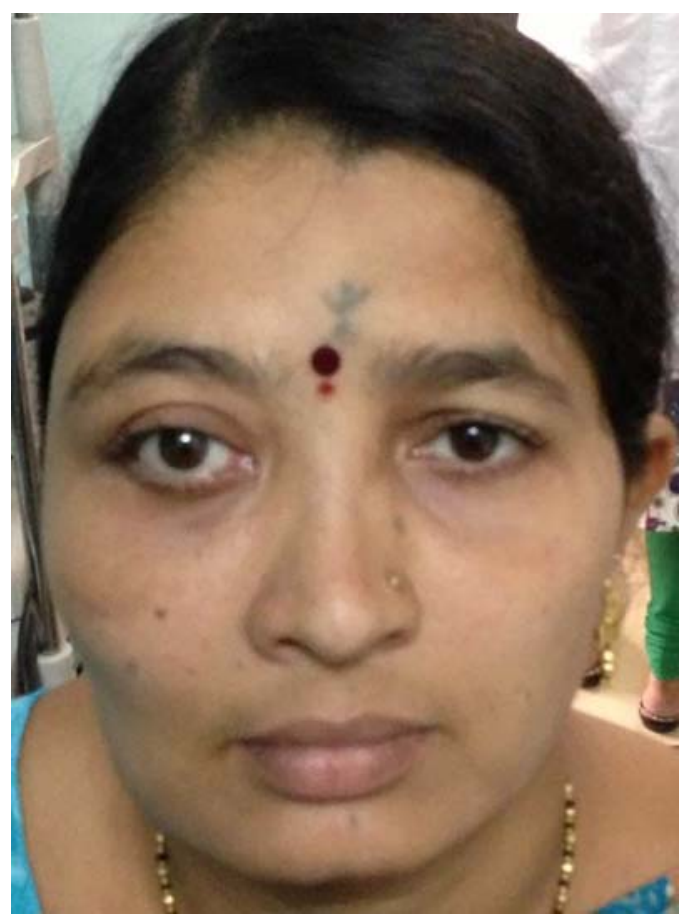

Figure 12 Extraoral view of the patient post 1 year of follow-up.

cases of PFD show craniofacial involvement. ${ }^{1}$ Although spine involvement in FD is rare (around 1.4-5.5\%), it can lead to severe morbidity such as kyphoscoliosis, scoliosis, fractures of deformed vertebral bodies, spinal nerve compression syndromes, secondary nerve compression syndrome, etc. ${ }^{3}{ }^{13}$ Bone pain, pathological fractures and bone deformities are the most common signs of FD. Facial pain, headache, cranial asymmetry, facial deformity, tooth displacement, and visual or auditory impairment are the probable signs and symptoms for FD of cranial and facial bones. ${ }^{14}$ Our case presents FD affecting



Figure 13 Pathogenesis of fibrous dysplasia. 
Table 1 Details of clinicoradiological and pathological features of craniofacial polyostotic fibrous dysplasia and present case

\begin{tabular}{|c|c|c|c|}
\hline & Clinical features & Radiographic features & Histopathological features \\
\hline $\begin{array}{l}\text { Craniofacial } \\
\text { polyostotic fibrous } \\
\text { dysplasia }\end{array}$ & $\begin{array}{l}10 \text { years to adolescence } \\
\text { Equal sex predilection } \\
\text { Swelling } \\
\text { No pain } \\
\text { Deformity present } \\
\text { Proptosis } \\
\text { Visual disturbance } \\
\text { Hearing problem } \\
\text { Bones involved: maxilla, mandible, sphenoid, } \\
\text { ethmoid and facial bone } \\
\text { Least involved: temporal, occipital and spine }\end{array}$ & $\begin{array}{l}\text { Pagetoid pattern } \\
56 \% \\
\text { Ground glass or orange } \\
\text { peel appearance } \\
\text { Mottled radiopaque } \\
\text { pattern with ill-defined } \\
\text { borders } \\
\text { Sclerotic pattern } \\
23 \% \\
\text { Mixed radiopaque/ } \\
\text { radiolucent lesion } \\
\text { Ill-defined with sclerotic } \\
\text { borders } \\
\text { More in head and neck } \\
\text { Cystic pattern } \\
\quad 21 \% \\
\text { Radiolucent with either } \\
\text { ill-defined or well-defined } \\
\text { borders } \\
\text { Unilocular or multilocular }\end{array}$ & $\begin{array}{l}\text { Chinese writing or Chinese alphabets pattern } \\
\text { Most common type } \\
\text { each other } \\
\text { Active bone resorption by the osteoclast cells along } \\
\text { infrequent presence of osteoblast } \\
\text { Fibrous connective tissue prevails over thin, irregular, } \\
\text { and disconnected trabeculae } \\
\text { Pagetoid pattern } \\
\text { Resemblance to the histopathological feature of } \\
\text { Paget's disease } \\
\text { Bone predominates over the fibrous component of } \\
\text { Most common feature is dense, sclerotic trabecular } \\
\text { bone seen } \\
\text { The Sharpey fibres and stellate/retracted osteoblasts } \\
\text { can also be appreciated along the trabecular surfaces } \\
\text { of the bone } \\
\text { Hypercellular pattern } \\
\text { Similar to pagetoid type but it appears to be } \\
\text { discontinuous } \\
\text { The connective tissue stroma appears to be similar to } \\
\text { that of Chinese alphabet variant } \\
\text { Osteoblast cells in single or layers can be seen } \\
\text { associated to one side showing activity in the } \\
\text { homologous sides of the trabeculae }\end{array}$ \\
\hline Present case & $\begin{array}{l}30 \text { years, female } \\
\text { Swelling with proptosis } \\
\text { Bones involved: parietal, frontal, ethmoid, sphenoid, } \\
\text { occipital, temporal, zygomatic, maxilla, mandible, } \\
\text { sternum, rib, thoracic vertebrae }\end{array}$ & $\begin{array}{l}\text { Features are similar to the } \\
\text { pagetoid pattern }\end{array}$ & $\begin{array}{l}\text { Features similar to pagetoid pattern } \\
\text { Irregular, broad, interconnected. Bony trabeculae in a } \\
\text { collagenous stroma with varying degree of cellularity and } \\
\text { vascularity } \\
\text { Reversal lines resembling the mosaic pattern of Paget's } \\
\text { disease } \\
\text { No evidence of osteoblastic rimming and lamellar bone } \\
\text { Fusion of lesional and host bone was seen }\end{array}$ \\
\hline
\end{tabular}

multiple cranial and facial bones along with rib, sternum and cervical vertebrae which are less commonly involved.

Both MFD and PFD have equal sex predilection. MFD occurs in second and third decade of life while PFD usually has its onset in first decade with lesion enlarging until puberty is attained. ${ }^{1}$ In present case FD has occurred in a 30 -year-old female patient with lesion that has gradually increased in a span of year.

Radiologically, on basis of the proportion of bone and soft tissue component, FD is classified in three variants, pagetoid (ground glass), sclerotic and cystic variety. ${ }^{15} 16$ Pagetoid (56\%) being most commonly occurring variant, is formed due to mixture of dense and radiolucent areas of fibrosis. Sclerotic (23\%) shows homogenous dense appearance, while, cystic variety (21\%) appears as radiolucency surrounded by dense bone shell. ${ }^{15}$ Radiological examination in the present case showed appearance similar to the pagetoid variant.

On the basis of time of occurrence of mutation and the histopathological ratio of bone and fibrous component, FD is classified in three types: Chinese letter/alphabet pattern, pagetoid pattern and hypercellular pattern. Dominant feature in Chinese letter/alphabet pattern is 'Chinese pattern' of bone trabeculae. The bone appears to be disconnected and thin, separated from each other by large, loose fibrous connective tissue stroma. In pagetoid type, the bony trabeculae appear broad and dense with occurrence of reversal lines similar to the mosaic pattern in Paget's disease of bone. The bone component is comparatively higher than fibrous component. The amount of bone and fibrous component in hypercellular variant is similar to that of pagetoid variant. However, the bone trabeculae are discontinuous and often parallel. The histological features of present case were similar to pagetoid variant of PFD. ${ }^{4}$

Overall clinicoradiological and pathological features ${ }^{1-4} 8$ 14-16 of craniofacial PFD and the present case are summarised in table 1 .

\section{Learning points}

- Spine involvement, being a rare but grave finding in craniofacial polyostotic fibrous dysplasia (PFD), mandates a thorough clinical, radiological and histopathological examination in every case.

- The pathological expression of GNAS $1 \alpha$ mutation has an impact on the overall features of fibrous dysplasia (FD). Hence, the recognition of different patterns and features is essential for proper understanding, classification and preventive approaches (genetic precounseling or gene therapy) of FD.

- Redefining classification of FD based on histopathological features and identification of its diversity in relation to event of genetic mutation and with different anatomical sites for academic interest. 


\section{Unusual presentation of more common disease/injury}

Cases of FD that do not present any functional distress, deformity or fractures should be monitored periodically. Surgical intervention should be considered if the lesion is encroaching on the adjacent structures and causing distress. ${ }^{17}$ The present case was managed by cosmetic recontouring of facial bones. The patient is on routine follow-up since 1 year and has not reported any distress.

Competing interests None declared.

Patient consent Obtained.

Provenance and peer review Not commissioned; externally peer reviewed.

\section{REFERENCES}

1 Feller L, Wood NH, Khammissa R, et al. The nature of fibrous dysplasia. Head Face Med 2009;5:22.

2 Riddle ND, Bui MM. Nature of fibrous dysplasia. Arch Pathol Lab Med 2013;137:134-8.

3 Wu FL, Liu ZJ, Liu XG, et al. Polyostotic fibrous dysplasia involving the thoracic spine with myelopathy: case report and review of the literature. Spine J 2014;14:11-15.

4 Riminucci M, Liu B, Corsi A, et al. The histopathology of fibrous dysplasia of bone in patients with activating mutations of the Gs agene: site-specific patterns and recurrent histological hallmarks. J Pathol 1999;187:249-58.

5 Naik MN, Tourani KL, Chandra Sekhar G, et al. Interpretation of computed tomography imaging of the eye and orbit. A systematic approach. Indian J Ophthalmol 2002;50:339-53.
6 Eversole R, Su L, EIMofty S. Benign fibro-osseous lesions of the craniofacial complex. A review. Head Neck Pathol 2008;2:177-202.

7 Neville BW, Damm DD, Allen CM, et al. Oral and maxillofacial pathology. Chapter. 14, Bone pathology. 2nd edn. Philadelphia: W.B. Saunders Company, 2002;563-4.

8 Lichtenstein L. Polyostotic fibrous dysplasia. Arch Surg 1938;36:874-98.

9 Kruse A, Pieles U, Riener MO, et al. Craniomaxillofacial fibrous dysplasia: a 10-year database 1996-2006. Br J Oral Maxillofac Surg 2009:47:302-5.

10 Bianco P, Riminucci M, Majolagbe A, et al. Mutations of the GNAS1 gene, stromal cell dysfunction, and osteomalacic changes in non-McCune-Albright fibrous dysplasia of bone. J Bone Miner Res 2000;15:120-8.

11 Weinstein $L S$. G(s) alpha mutations in fibrous dysplasia and McCune-Albright syndrome. J Bone Miner Res 2006;21:120-4.

12 Abdelkarim A, Green R, James Startzell S, et al. Craniofacial polyostotic fibrous dysplasia: a case report and review of the literature. Oral Surg Oral Med Oral Pathol Oral Radiol Endod 2008; 106:49-55.

13 Leet Al, Magur E, Lee JS, et al. Fibrous dysplasia in the spine: prevalence of lesions and associations with scoliosis. J Bone Joint Surg Am 2004:86-A:531-7.

14 DiCaprio MR, Enneking WF. Fibrous dysplasia. Pathophysiology, evaluation, and treatment. J Bone Joint Surg Am 2005;87:1848-64.

15 Brown EW, Megerian CA, Mckenna MJ, et al. Fibrous dysplasia of temporal bone: imaging findings. AJR 1995;164:679-82.

16 Hanifi B, Samil KS, Yasar C, et al. Craniofacial fibrous dysplasia. Clin Imaging 2013;37:1109-15.

17 Menon S, Venkatswamy S, Ramu V, et al. Craniofacial fibrous dysplasia: surgery and literature review. Ann Maxillofac Surg 2013;3:66-71.

Copyright 2015 BMJ Publishing Group. All rights reserved. For permission to reuse any of this content visit http://group.bmj.com/group/rights-licensing/permissions.

BMJ Case Report Fellows may re-use this article for personal use and teaching without any further permission.

Become a Fellow of BMJ Case Reports today and you can:

- Submit as many cases as you like

- Enjoy fast sympathetic peer review and rapid publication of accepted articles

- Access all the published articles

- Re-use any of the published material for personal use and teaching without further permission

For information on Institutional Fellowships contact consortiasales@bmjgroup.com

Visit casereports.bmj.com for more articles like this and to become a Fellow 